\title{
A politica da assistência periférica ${ }^{1}$
}

\author{
The Politics of Peripheral Care
}

\begin{abstract}
AbdouMaliq Simone
É urbanista e tem particular interesse nas formas emergentes de vida coletiva nas cidades do Sul Global. Simone é Senior Professorial Fellow no Urban Institute da Universidade de Sheffield e Professor Visitante de Estudos Urbanos no Centro Africano de Cidades da Universidade de Capetown. Suas publicações incluem: For the City Yet to Come, Duke University Press, 2004, and City Life from Jakarta to Dakar: Movements at the Crossroads: Routledge, 2009, Jakarta: Drawing the City Near: University of Minnesota Press, 2014, New Urban Worlds: Inhabiting Dissonant Times, Polity 2017 (with Edgar Pieterse), and, Improvised Lives: Rhythms of Endurance in an Urban South (Polity 2018).
\end{abstract}

\section{Tradução \\ Leonardo Giucci}

Submetido em 16 de Setembro de 2019

Aceito em 15 de Outubro de 2019

\section{RESUMO}

Os pobres e trabalhadores das cidades do Sul Global encontram-se em espaços urbanos que são convencionalmente interpretados como locais para residir ou habitar. Mas e se pensássemos nos distritos populares de maneiras mais amplas que contemplasse o que realmente acontece dentro deles? Nessas cidades, os distritos populares são o cenário de operações mais incertas que acontecem sob a cobertura da escuridão, gerando alianças estranhas entre corpos, materiais e coisas díspares e expandindo o sensório urbano e suas

\footnotetext{
${ }^{1}$ Publicado originalmente como capítulo do livro SIMONE, AdouMaliq. Improvised Lives: Rhythms of
} Endurance in an Urban South (After the Postcolonial). Cambridge, UK: Polity Press, 2019.

Dossiê Espaço Urbano e Imaginação Cultural - https://revistaecopos.eco.ufrj.br/

ISSN 2175-8689 - v. 22, n. 3, 2019.

DOI: 10.29146/eco-pos.v22i3.27409 
capacidades de vivacidade.

PALAVRAS-CHAVE: Periferia; Precariedade; Assistência Social.

\section{ABSTRACT}

The poor and working people in cities of the South find themselves in urban spaces that are conventionally construed as places to reside or inhabit. But what if we thought of popular districts in more expansive ways that capture what really goes on within them? In such cities, popular districts are the settings of more uncertain operations that take place under the cover of darkness, generating uncanny alliances among disparate bodies, materials and things and expanding the urban sensorium and its capacities for liveliness. KEYWORDS: Periphery; Precarity; Social Assistance.

\section{Desfazendo danos}

O que significa coletar evidências de situações danosas? Como essa evidência se constitui; como ela se manifesta em experiências corporais específicas e para diferentes constituições? Parece haver pouco para mitigar nosso vício coletivo em testemunhar os repetidos cenários em que a vida é exposta. Onde a identificação e busca por um tipo particular de terror se transforma em uma situação muito pior do que a ameaça inicial; onde todos os atos de contenção se ramificam para destituir um número crescente de pessoas de meios de subsistência viáveis e relações com o local.

Obsessões de elite com qualquer movimento social que exemplifique uma absoluta intolerância em aceitar injustiças, e que podem se transformar em uma ferocidade frequentemente característica de tal singularidade de visão, tendem a levar a intervenções que passam a depender justamente daquilo que é obsessivamente temido como a única maneira de impedir um desastre muito pior. Basta traçar uma linha de Dakar a Djibuti e de Mekkah a Peshawar para entender como reivindicações diversas e parciais à Ummah Muçulmana são convertidas em uma histeria global que exige intervenções que propagam danos ecológicos, humanitários e políticos que não podem ser retificados. 
Embora dano e perigo possam ser imediatamente evidentes sem a necessidade de reflexão, existem situações em que o dano é mais difuso e não é facilmente discernível sem dispositivos inovadores de detecção ou práticas especulativas. Essas práticas envolvem o surgimento de novas formas de cooperação social capazes de validar e transformar corpos provisórios de evidência em instrumentos políticos acionáveis (GABRYS, 2014, p. 217). A liminar de Gabrys pode ser um importante ponto de partida para repensar uma política de assistência na medida em que ela formula assistência como um "modo especulativo de encontro que é diferentemente articulado em relação às entidades e coletivos que são informados por meio de práticas de monitoramento que buscam evidenciar experiências de dano. " (GABRYS, 2017, p. 177).

O que acontece quando situações ou épocas específicas ficam tão saturadas com toxicidade, e onde a toxicidade é ignorada porque prestar-lhe atenção significaria que o dinheiro frequentemente associado a ela seria desviado para outro lugar, ou onde o tóxico se transforma em um familiar, porém não menos letal companheiro? Todas as evidências que poderiam ser reunidas para instigar as pessoas a sair, desistir ou se rebelar podem simplesmente "ficar paradas" como uma testemunha silenciosa das condições ou eventos em questão, bem como dos corpos afetados - agora simplesmente apêndices da lista de medidas de monitoramento aplicadas.

Não digo isso para que se aceite o desastre. Mas apenas para reconhecer o excesso de preocupação com ele, que então muitas vezes parece desqualificar a indiferença real ou fingida, onde a indiferença é vista apenas como resignação por parte daqueles que continuam vivendo através ela, por ela e com ela. Embora seja importante para os residentes de condições aparentemente deletérias demonstrar o que realmente lhes importa e terem meios de converter a atenção obtida em melhorias, os tipos de cuidados e intervenções que essas demonstrações podem instigar pode por vezes estar limitado àquilo que faz sentido apenas fora das experiências vividas por esses próprios residentes. Pode haver situações onde a 
indiferença é simplesmente isso - indiferença; em diferença com as expectativas normativas de como alguém deve reagir, como se deve cuidar das coisas.

São residentes que podem então ser acusados de falsa consciência ou de internalizarem a dominação. Em outras palavras, muitas tentativas de "melhorar as coisas" descartam aqueles que tentam forjar um tipo de senso no momento em que todo o "senso comum" parece desaparecer, ou que se situam além do escopo da assistência preventiva. Como conclui enfaticamente Musa al-Jawani, um ladrão de 18 anos da infame favela Gayati Mayo em Cartum: "Eu não quero uma vida; eu não quero nenhum vestígio de que eu estive aqui, muito embora, através da cidade, eu aprecie os rumores que ouço de que vários homens e mulheres importantes simplesmente não conseguem acreditar que alguns de seus pertences, os quais eu revendo por quase nada, de fato desapareceram, assim como qualquer vestígio do crime."

Às vezes, uma política de assistência é uma questão de concretizar novas linhas de conexão, como Asef Bayat (2015) descreve sobre um bairro pobre no Cairo durante o advento da Revolução Egípcia de 2011.

\begin{abstract}
As comunidades ashwaiyyat tais como Imbaba não abrigavam apenas os moradores rurais, analfabetos e abjetamente pobres, mas também segmentos dos 'pobres de classe média' - funcionários do governo, casais recém-casados e com educação, além de profissionais como advogados e professores - que não conseguiam arcar com os custos de moradia no mercado formal. Os membros dessa classe, transitando entre o mundo da 'classe média' e o dos 'pobres', conectavam criticamente os esforços locais de seus pais, parentes e vizinhos desprovidos ao mundo das universidades, jornalismo, ciberespaço, ativismo associativo e às ruas principais. (BAYAT, 2015, p. 37)
\end{abstract}

Mas, como Bayat continua a dizer, as centenas de protestos, greves, iniciativas coletivas, recuperações de espaço, geração de mercados e empreendimentos de rua, apropriação de terrenos e edifícios projetados pelos pobres após a revolução não puderam alterar os preconceitos institucionais maiores contra os pobres ou o modo como a gestão do próprio espaço urbano é amplamente dedicada a garantir a insuficiência de tais esforços coletivos

Dossiê Espaço Urbano e Imaginação Cultural - https://revistaecopos.eco.ufrj.br/

ISSN 2175-8689 - v. 22, n. 3, 2019.

DOI: 10.29146/eco-pos.v22i3.27409 
Uma política urbana deve então urgentemente permitir que o vasto reservatório de vitalidade que emana das ruas e dos distritos populares permeie a própria infraestrutura de tomada de decisões e estratégias de suprimento. Quer isso possa ser concretizado ou não, a possibilidade de tal política implica ao menos a perspectiva de uma recusa ativa dos modos de habitação em seus termos atuais, mesmo quando a criação desses modos em grande parte do Sul é autogerada e autodesenvolvida pela maioria dos residentes. Se não se assemelham claramente a recusas, muitos gestos como esses são feitos o tempo todo.

Pois surtos de efeito político nem sempre assumem os vernáculos reconhecíveis de autonomia, resistência e liberdade. Não teriam os ritmos de resistência, como observamos nas diferentes discussões até agora, provado serem mais sutis do que isso, mais hábeis em trabalhar o seu caminho através das diversas modalidades de expressão?

Como aponta Povinelli (2017), o liberalismo tardio investe na ilusão contínua da autonomia dos objetos, na contestação de posições definidas e nas possibilidades de tornar-se plural. Tudo isso é supostamente aberto a uma ampla gama de possíveis futuros, e particularmente à possibilidade de que um eu individual autônomo possa, através da vontade e da habilidade, determinar o curso de futuros particulares. Mas essa possibilidade se baseia em relegar tudo o que não está orientado em direção a essa individuação a um passado que não tem mais nada a dizer. Os exemplos que ela usa centram-se no pensamento indígena australiano.

Esse passado, então, é submetido à força a condições que restringem seus poderes de proposição e o tornam, se ele de fato perdurar de algum modo, como a "verdade" do passado, algo congelado em manifestações particulares, completas e autocontidas, incapazes de ser outra coisa além do que já são e sempre foram (POVINELLI, 2017). Ela continua a dizer:

As ilusões de nossa época são as autônomas e antagônicas. Outras ilusões podem ser mais adequadas. Vírus, gases, toxinas - esses são os nomes que damos às maneiras de aparecer e se espalhar; táticas de

Dossiê Espaço Urbano e Imaginação Cultural - https://revistaecopos.eco.ufrj.br/

ISSN 2175-8689 - v. 22, n. 3, 2019.

DOI: 10.29146/eco-pos.v22i3.27409 
divergir as energias dos arranjos da existência a fim de se estenderem; estratégias de copiar, duplicar e permanecer inativo, mesmo quando continuamente se ajustam, experimentam e testam suas circunstâncias; manobras para confundir e nivelar todas as diferenças que surgem entre as regiões, ao mesmo tempo se aproveitando cuidadosamente dos mínimos aspectos de suas diferenciações. (POVINELLI, 2017, p. 308)

Assim, também, as maneiras de aparecer e estender para uma "maioria" urbana - o que poderíamos chamar de autoconstrução no passado - assumem diferentes modos de visibilidade e atuação coletiva. Aqui, uso a noção de "coletivo" não como uma entidade coerente, mas como algo mais difratado e superposicional. 0 coletivo é um meio de implantar força, de dobrar vidas e coisas individuais discerníveis em espaços de operação que não são habitáveis em sentido estrito. Em outras palavras, a equação que liga a habitação à hospedagem de algo definível e que dá definição àquilo que habita, situando-a em uma ecologia complexa de interdependência e vida sustentável, é revertida em uma matemática urbana que situa residentes simultaneamente em multiplicidades emaranhadas de restrição e potencial, bem como em densas teias alternadas de governo e arbitrariedade. Enquanto uma vanguarda, um proletariado ou um movimento político podem não ser meros anacronismos, é necessário considerar os "corpos" cambiantes da encenação coletiva, todos os modos pelos quais pessoas e coisas podem operar em conjunto. Aqui uma noção mais ampla de solidez pode ser necessária, sólida não como carne, mas como uma batida ou um amálgama de corpo e máquina que emite batimentos, pulsações capazes de carregar as coisas, naquele estranho vórtice entre ser involuntariamente puxado e atos de carregamento mútuo, hijra, onde estar a caminho elimina qualquer captura.

\section{Ensaios Perigosos}

As paisagens urbanas são cada vez mais marcadas pela presunção de enclausuramento, (SEVILLA-BUITRAGGO, 2015), a marcação de território como a prerrogativa exclusiva de posse imune às articulações dos entornos mais amplos, exceto aquelas ditadas pelo estatuto ou pela vantagem econômica do(s) 
proprietário(s). Enclausuramento reflete a crença em um desapego delirante, onde aqueles que exercem direitos sobre o território podem se eximir de ter que negociar com a multidão de outros que exercem suas próprias reivindicações particulares de subsistência e imaginação em uma região urbana. Não apenas os despejos e deslocamentos aceleraram por meio de uma variedade de mecanismos, mas um número crescente de moradores adotou as possibilidades de enclausuramento como uma prática normativa, como uma modalidade de vida indicativa de seu valor e elegibilidade para fazer parte da cidade. Isso é o caso mesmo quando sua localização subsequente parece removê-los para longe do centro de gravidade da cidade.

De Istambul a Beijing, Bangkok, Jakarta, São Paulo e Brooklyn, o núcleo urbano está sendo separado de sua classe trabalhadora, classe média baixa e populações pobres - sua maioria. De despejos forçados à sedução de promessas de uma vida melhor a duras lembranças de gastos, a maioria é reconstituída na periferia em um processo de suburbanização em massa. Como tal, a política urbana será em grande parte uma política periférica, não apenas uma política na periferia, mas uma política cujas práticas devem se despojar de muitas das suposições que foram derivadas da primazia da "cidade". Essa última era uma política de sujeitos autorreflexivos, articulando futuros em termos de direitos e participação democrática. A periferia, por outro lado, é uma máquina de compostagem que processa os restos da vida da cidade em um extrato de estranhas contiguidades que não sabem o que fazer umas das outras, que não conhecem nenhum interesse em particular para defender ou negociar.

Pois a questão é: para onde vão todos os que sobraram da ocupação deslocada nos núcleos urbanos, deslocados com base em sua pobreza indecorosa, práticas perigosas, cálculos econômicos ou por abraçar uma existência mais individuada, acessível e maximizada para o consumo. A formação subsequente das periferias não diferencia claramente essas trajetórias distintas de êxodo.

Despesas massivas de prédios acessíveis para as classes médias baixas são intercaladas com zonas de captação rapidamente montadas para os pobres 
urbanos, todas elas se cruzando com uma variedade de terrenos industriais, fábricas realocadas, zonas de lazer em ruínas, lixões, armazéns e vestígios de condomínios fechados de alto padrão. A maior parte do ambiente construído não é construído para durar. Grandes propriedades de pequenos pavilhões que prometiam casa própria e ativos fungíveis para os assalariados estão decaindo rapidamente e sendo abandonadas em menos de uma década após a sua conclusão. As populações estão se inserindo nos interstícios nebulosos das terras de ninguém, produzidos pela exigência de separar ainda mais as classes merecedoras das classes não merecedoras, ao lado de várias infraestruturas de transporte, bancos de terrenos e vastas séries de espaços industriais e comerciais que não estão nem totalmente operacionais nem totalmente esgotados.

As populações urbanas estão sendo eliminadas, talvez por razões que pouco têm a ver com a vida urbana em si, e sim com o uso da reconstituição da área urbana para um projeto planetário muito maior de descartar a maioria em favor da sobrevivência de alguns poucos. Afinal, a conversão de núcleos urbanos em estruturas efêmeras financializadas e espetaculares geralmente não funciona em termos de qualquer outra função aparente além de uma conversão abstrata incessante. Eles permanecem inúteis em qualquer outro sentido. Eles sustentam portfólios projetados para subsidiar o fim de uso; um programa planetário que não vê utilidade na continuidade de existência da maioria. Apesar dos relatórios imobiliários relatando a urgência de maiores volumes de metragem quadrada comercial e outras amenidades para os ricos, muitos projetos permanecem quase vazios, cultivando uma tolerância ao vazio.

Enquanto a cidade era o local para forjar uma noção generalizada de uma humanidade comum para qual a cidade seria sua evidência principal, essa geração de vazios no núcleo urbano e a rotatividade acelerada do ambiente material parecem ser um preparo para o abandono de qualquer humanidade generalizada. É o local pelo qual os privilegiados podem "ir para as colinas", cortar "os nativos na passagem" e fazê-lo sem a aparência de estar cometendo um crime, já que o crime agora é de responsabilidade de toda a humanidade.

Dossiê Espaço Urbano e Imaginação Cultural - https://revistaecopos.eco.ufrj.br/ ISSN 2175-8689 - v. 22, n. 3, 2019.

DOI: $10.29146 /$ eco-pos.v22i3.27409 
Como Cohen e Colebrook (2017) apontam, "Olhando para as próximas décadas, o desmantelamento populacional passivamente construído não precisa deixar impressões digitais visíveis e não apresenta agonia ética para uma 'espécie' avançada relacionada, ou, mais precisamente, por uma versão turbinada do que, desde o início, tem sido a espécie que não é uma, uma vez que tudo com o que ela se identificou e transformou em propriedade como artes de arquivo, mnemotecnologias, sensoria semiestética e totalizações digitais eram já cadeias de significância materialista, nem humanas, explicitamente, nem vivendo como tal" (COHEN \& COLEBROOK, 2017, p. 140-141).

A periferia é, então, não apenas uma espacialização particular do urbano, mas um retrocesso da própria base ideológica da vida urbana como o grande sintetizador, como o local da realização cosmopolítica. A periferia também recua como fronteira. Os primeiros residentes podiam calcular os locais mais estratégicos, onde se posicionar de acordo com o que podiam pagar, mas também considerar a acessibilidade em termos de proximidade ao transporte ou trabalho, ao eventual crescimento de uma área específica ou à disponibilidade de serviços e seus custos relativos. Os moradores da periferia não apenas procuravam um lugar para morar, mas também uma oportunidade de projetar um mundo para si mesmos, com base em especulações sobre como a periferia seria eventualmente "preenchida" e como eles queriam se situar de acordo com isso.

\section{Rumo a uma política periférica}

Agora, as periferias estão cada vez mais abarrotadas, invadidas e, em muitos aspectos, uma política urbana começa com essa aglomeração, com uma situação em que os moradores precisam cada vez mais "pegar o que conseguem" para se situar da melhor maneira possível em ambientes onde antecipações sobre o futuro parecem quase impossíveis. Assim, uma política começa aqui na dissolução da volição e do aprisionamento não intencional, onde os moradores que chegaram 
por diferentes trajetórias de ímpeto ficam presos uns aos outros em um estado aparentemente permanente do provisório.

$\mathrm{Na}$ superfície, algumas dessas periferias parecem ingovernáveis. Frequentemente visito familiares que moram em uma dessas periferias, Citayam, perto do fim de uma das linhas de ônibus em Jacarta. Está chovendo e a rua lamacenta que corre em frente à estação está engarrafada, assim como todas as estradas circundantes. Ninguém se move esperando pelo aplicativo de transporte, ônibus baratos ou moto-táxis. Os ônibus parados são imediatamente convertidos em lojas improvisadas vendendo cigarros que "caíram do caminhão" e bilhetes de loteria de Cingapura. A multidão reunida sob guarda-chuvas em frente à estação circula em torno de corretores de terras que oferecem fundos comunitários nos antigos campos de arroz. Professores das escolas islâmicas vizinhas distribuem folhetos, enquanto uma linha interminável de trabalhadores carrega mercadorias entre a estação e os mercados próximos. Os burocratas municipais locais dispensam seus escritórios e montam pequenas mesas sob os toldos das lojas de varejo espalhadas em todas as direções da estação, tentando alistar passageiros que entram e saem em vários esquemas, desde ofertas de saúde e imunização até campanhas de segurança local.

Essa área costumava ser uma cidade de mercado que servia aos campos de arroz circundantes. A área é frequentemente inundada e as dezenas de milhares de novos moradores, suas casas, lojas e veículos simplesmente exacerbaram a umidade. Muito poucas estradas correm em linha reta e muito poucas podem realmente acomodar veículos que viajam nas duas direções. 0 que significa que estar perto do trem é uma determinação que muda diariamente. A área tornou-se um receptáculo para todos os tipos de projetos e circunstâncias de vida. As pessoas estão na fuga de algo e imbuíram Citayam com fantasias de todos os tipos. Todos os partidos políticos desceram em massa para estabelecer filiais e matricular eleitorados, mas poucos moradores estão interessados. Tampouco estão interessados nos vernáculos religiosos populistas que estão varrendo as partes mais antigas de Jakarta.

Dossiê Espaço Urbano e Imaginação Cultural - https://revistaecopos.eco.ufrj.br/

ISSN 2175-8689 - v. 22, n. 3, 2019.

DOI: 10.29146/eco-pos.v22i3.27409 


\section{DOSSIE}

É impossível ir trabalhar no trem sem ser "interceptado" com algum tipo de esquema, alguma nova proposta para ingressar em lotes, reduzir os custos de alimentação ao comprar em conjunto com outros, de colocar um pedido para alguém indo fazer compras em Kuala Lumpur. Todas essas operações são realizadas de improviso, não são os subprodutos da vida estabelecida na vizinhança. Todos estão a caminho de algum lugar, e visto que todo mundo precisa de um lugar para estacionar seus pertences, de seus filhos ou pais, seus documentos ou sonhos, Citayam é, em certo sentido, um grande estacionamento para veículos que mal podem se mover. A estação é o público, e suas deliberações estão por todo o lado enquanto seus membros vão e vêm de muitos lugares.

Configurações espaciais e o decantar de territórios discerníveis são muito menos importantes que as modulações rítmicas do movimento. É claro que é importante encontrar um lugar para se identificar como "casa", mas encontrar os ritmos certos de circulação, evasão e interação é a chave para encontrar lugares para efetivamente "viver", para gerar meios de subsistência. Em uma cidade onde mais e mais pessoas não ficam em casa, encontrar um lugar estratégico para ficar é uma questão de ritmo. Governar aqui é uma questão de os residentes encontrarem meios de manter o fluxo, de saber como improvisar quando os itinerários são inevitavelmente interrompidos, de fazer o possível dentro dos desvios e momentos de inatividade, de converter a inatividade em oportunidades para interagir com outros desconhecidos onde não há obrigações, não há promessas de reciprocidade e onde é provável que ninguém te descubra ou te julgue por quaisquer riscos impulsivos que você possa assumir.

Muitos podem ter inicialmente procurado Citayam como a realização do imperativo de tornar-se verdadeiramente classe média e escapar das residências que exigem muito trabalho em bairros populares do núcleo urbano. Mas, no fim das contas, a maioria não consegue sair definitivamente de um "diálogo" rodopiante com histórias discrepantes de implantação. Eles logo descobrem que essa periferia é impenetrável a horizontes de longo prazo e acabam por "trabalhar" a linha de trem como meio de gerar circulações idiossincráticas pela região e 
através de uma rede provisória de salas de pensão, empregos extras, oportunidades para os filhos e pequenos investimentos aqui e ali usando toda a região como tela e esses itinerários constantemente reinscritos como sua "verdadeira casa". É estonteante tentar descobrir como esses múltiplos itinerários, cronogramas e interseções frouxas operam em qualquer tipo de comunhão, ou mesmo seguir os circuitos de uma única casa, sem falar naqueles seguidos por moradores que vivem nominalmente no mesmo distrito - agora, algo cujas fronteiras e definição estão mais difusas do que nunca.

Apesar da expropriação massiva dos fundos de hipoteca da classe trabalhadora para o que se tornariam distritos inabitáveis, as periferias se apresentam como algo mais do que simples locais de despejo e, no entanto, não está claro até que ponto elas se oferecem como um terreno político específico. Em Citayam, a política pode ser mais sobre como garantir que os moradores cheguem ao trem, sobre como atrair as energias geradas nesse processo para consolidar a infraestrutura e os serviços urbanos de uma maneira que sejam capazes de acompanhar todas as reviravoltas da paisagem material e social emergente sem endireitar suas perspectivas e contiguidades de funções díspares (AMIN \& THRIFT, 2016). Implica em não amarrar os residentes a lutas intermináveis para garantir suas posições provisórias, em correlacionar segurança com manter a opacidade relativa de ambientes complexos que impedem grandes consolidações de terras. Significa manter a periferia da periferia como fonte de alimentos e sistemas de marketing improvisados que mantêm os custos baixos. Significa envolver as deliberações improvisadas que os residentes em espaços materiais e afetivos excessivamente congestionados conduzem para conceder um ao outro algum "direito de passagem", algum espaço de operação como uma forma de cuidado. Significa ver o cuidado no modo como os furos são feitos em todos os limites que marcam um assentamento específico e ver essas aberturas como formas de cuidado.

Significa olhar como a própria intensidade das forças segregadoras, das expulsões, das apropriações de terras e da gentrificação - que são na verdade os 
descritores predominantes do desenvolvimento urbano contemporâneo - também ricocheteiam de maneiras estranhas, sugerindo, por um momento, não o romance com a mistura urbana cosmopolita, mas uma densidade contingente de diferenças que parecem não saber narrar como todas elas chegaram ao mesmo "bairro" (HART \& NEGRI, 2017). Interesses monetários podem prevalecer, bem como grandes esquemas de estilos de vida autocontidos, enclausurados e homogêneos, que oferecem aos futuros moradores contato direto com um mundo global. Mas o outro lado de todas essas concessões e adaptações necessárias para esse "fazer parte do mundo real" reflete uma pluralidade de pequenas recusas, "câmbios de direção", ascensões e declínios rápidos, onde todos os tipos de estranhos acabam tendo que pegar "o mesmo trem".

É uma questão de tentar andar na corda bamba entre recusar a incorporação às ordens de poder que tornam os residentes periféricos, que os forçam às periferias, e as tentativas de se apropriar das energias e manifestações criativas dos residentes das periferias por essas mesmas ordens como meio de se retirar de qualquer responsabilidade de governar democraticamente (GAGO, 2015; KANNGIESER \& BUERET, 2017).

Esse navegar na corda bamba, no entanto, não possui uma única figura de resolução. É uma tensão incessante, pois essa tensão é o ritmo de práticas que parecem não recusar nem consentir. Como Barber aponta (2017): política é o problema que o ser não pode resolver, e que é negado pela participação e pelo trânsito em direção à resolução. Qual é a essência da política? Não é intervenção na distribuição do ser pelas possibilidades alternativas de ser; é antes, insistência em um não que "precede" - que antecede, que é independente - da transitividade para o/do ser.

A segregação é real, mas em cidade após cidade ela também é repleta de vazamentos, uma vez que as construções, sejam caras ou baratas, frequentemente falham em manter do lado de fora os "elementos" ou são assombradas por espíritos debilitantes, montanhas de dívida ou tédio asfixiante. Mesmo quando as classes consumidoras expressam satisfação e alívio por terem escapado dos 
negócios confusos da antiga malha urbana, suas ansiedades sobre serem "sujeitos suficientemente bons" exercem seu próprio desgaste em toda a sociabilidade disponível. A grande maioria dos residentes é inclinada ao uso de fármacos, acentuando uma linha oscilante entre generosidade exorbitante e paranoia. Ainda assim, um senso urbano não pode ser sobrecarregado por cálculos intermináveis. As decisões políticas raramente são resultado de deliberação prolongada, e sim determinações para interromper o pensamento recursivo - religioso, racional ou algorítmico - no momento. As exposições são cruas e sem filtro. 0 clima afetivo predominante pode levar à conclusão de que a maioria dos residentes está acomodada por detrás das portas fechadas. Mas os cafés, bares e restaurantes improvisados de Citayam, Les Eucalyptus, Abobo (Abidjan) e Liberdade (Salvador - Bahia) estão repletos de mesas cobertas com mapas, notas, convites para apresentação de propostas e esquemas.

Em um jogo de política estatal, onde as disponibilidades e o território são continuamente repartidos para diferentes facções, onde o excesso de confiança das grandes empreiteiras é cada vez mais pontuado por uma ansiedade incessante de acertar o timing, de ter que presidir sobre suturas intrincadas de dinheiro, terra, trabalho, tecnologia, regras e acordos políticos, manter as periferias como espaços comprimidos de subsistência, manobras e antecedentes é fundamental. Elas não apenas oferecem uma possível proteção contra os demolidores regimes de shoppings homogeneizados, parques industriais e zonas de processamento de exportação, mas também são instrumentos de alavancagem nesse mesmo jogo.

Citayam oferece um fluxo contínuo de pequenas recusas para ser o braçodireito no terreno para esse jogo político - um jogo financiado por autoridades estatais, orçamentos de capital e subsídios implícitos à acumulação gerada por imóveis. As autoridades municipais, na medida em que existem em Citayam, frequentemente jogam com as ambiguidades de leis e políticas compensatórias relativas à disposição de terra para trabalhar em "projetos" heterogêneos, ao invés de oferecer grandes pedaços de terra para consolidações de alta classe. Famílias agrícolas de longa data sublocam terras para múltiplas funções, cada função 
atuando como um possível efeito multiplicador da outra e um freio ao expansionismo dos demais. Os inquilinos de novas habitações baratas construídas por empreiteiros oportunistas rapidamente decidem deixar de ficar presos a casas que rapidamente se deterioram e fazem seus próprios acordos por debaixo dos panos para definir fatos, formando suas próprias empresas para desenvolver pequenas moradias e lojas co-financiadas por instituições terciárias que desejam abrir novas agências. É um mundo de "alianças estranhas" que frequentemente se desfazem em questão de dias, deixando seus próprios resíduos de derrota. Mas elas ocorrem dentro de uma atmosfera mais abrangente onde o medo do fracasso não é dominante, não impede iniciativas, o continuar tentando.

A vida urbana, independentemente de como estiver configurada e das promessas de eficiência automatizada, continua exigindo trabalho intenso. Embora os moradores de lugares como Citayam demonstrem muitas vezes sua disposição para descer nas ruas, para participar de longas e prolongadas batalhas por pequenas vitórias, não é razoável esperar uma política de antagonismos prolongados nas barricadas. Assim como eles aceitam o que a periferia tem a oferecer, que é em grande parte uma única linha de trem e um terminal excessivamente congestionado que se ramifica em intensificadas linhas fragmentadas de conexão e coerência, também nós deveríamos ser capazes de aceitar o que eles oferecem como prática política, como uma série de ritmos que permitem sentimentos e práticas surpreendentes, frustrantes e às vezes confusas dos residentes que cuidam e perduram uns com os outros.

\section{Referências bibliográficas}

BARBER, Daniel. Assembling No: Remarks on Diaspora and Intransivity. Substance 46, p. 155-165, 2017.

BAYAT, Asef. Plebeians of the Arab Spring. Current Anthropology 56, v.11, p. 33 43, 2015.

COHEN, Tom; COLEBROOK, Claire. Vortices: On "Critical Climate Change", as a Project. South Atlantic Quartely 116, p. 129-143, 2017.

\section{Dossiê Espaço Urbano e Imaginação Cultural - https://revistaecopos.eco.ufrj.br/}


GABRYS, Jennifer. Citizen Sensing, Air Pollution and Fracking: From "Caring about Your Air" to Speculative Practices of Evidencing Harm. Sociological Review 65:17292, 2017.

Programming Environments: Environmentality and Citizen Sensing in the Smart City. Environment and Planning D: Society and Space 32: 30-48, 2014.

GAGO. Verônica. Financialization of Popular Life and the Extractive Operations of Capital: A Perspective from Argentina. South Atlantica Quartely 114, p. 11-28, 2015.

KANNGIESER, A.; BEURET, N. Refusing the World: Silence, Commoning, and the Anthropocene. South Atlantic Quarterly, 116 (2), p. 363-380, 2017.

POVINELLI, Elizabeth. The Ends of Humans: Anthropocene, Autonomism, Antagonism, and the Illusions of Our Epoch. South Atlantic Quarterly, 116 (2), p. 293-310, 2017.

SEVILLA-BUITRAGO, A. Capitalis Formations of Enclosure: Space and the Extinction of the Commons. Antipode, 47(4), p. 829-1100, 2015. 